\title{
Antioxidant responses to heat and light stress differ with habitat in a common reef coral
}

\author{
Thomas D. Hawkins ${ }^{1,2}$ - Thomas Krueger ${ }^{1,3}$ - Shaun P. Wilkinson ${ }^{1}$. \\ Paul L. Fisher ${ }^{1,4} \cdot$ Simon K. Davy ${ }^{1}$
}

Received: 25 February 2015 / Accepted: 2 September 2015/Published online: 11 September 2015

(C) Springer-Verlag Berlin Heidelberg 2015

\begin{abstract}
Coral bleaching - the stress-induced collapse of the coral-Symbiodinium symbiosis-is a significant driver of worldwide coral reef degradation. Yet, not all corals are equally susceptible to bleaching, and we lack a clear understanding of the mechanisms underpinning their differential susceptibilities. Here, we focus on cellular redox regulation as a potential determinant of bleaching susceptibility in the reef coral Stylophora pistillata. Using slow heating $\left(1^{\circ} \mathrm{C} \mathrm{d}^{-1}\right)$ and altered irradiance, we induced bleaching in S. pistillata colonies sampled from two depths [5-8 $\mathrm{m}$ (shallow) and 15-18 $\mathrm{m}$ (deep)]. There was significant depth-dependent variability in the timing and extent of bleaching (loss of symbiont cells), as well as in host enzymatic antioxidant activity [specifically, superoxide dismutase and catalase (CAT)]. However, among the coral fragments that bleached, most did so without displaying any evidence of a host enzymatic antioxidant response. For
\end{abstract}

Communicated by Biology Editor Dr. Line K. Bay

Electronic supplementary material The online version of this article (doi:10.1007/s00338-015-1345-4) contains supplementary material, which is available to authorized users.

Simon K. Davy

simon.davy@vuw.ac.nz

1 School of Biological Sciences, Victoria University of Wellington, Wellington 6140, New Zealand

2 College of Earth, Ocean and Environment, University of Delaware, Lewes, DE 19958, USA

3 Laboratory for Biological Geochemistry, School of Architecture, Civil and Environmental Engineering (ENAC), École Polytechnique Fédérale de Lausanne (EPFL), 1015 Lausanne, Switzerland

4 School of Civil Engineering, University of Queensland, Brisbane, QLD 4072, Australia example, both deep and shallow corals suffered significant symbiont loss at elevated temperature, but only deep colonies exposed to high temperature and high light displayed any up-regulation of host antioxidant enzyme activity (CAT). Surprisingly, this preceded the equivalent antioxidant responses of the symbiont, which raises questions about the source(s) of hydrogen peroxide in the symbiosis. Overall, changes in enzymatic antioxidant activity in the symbionts were driven primarily by irradiance rather than temperature, and responses were similar across depth groups. Taken together, our results suggest that in the absence of light stress, heating of $1{ }^{\circ} \mathrm{C} \mathrm{d}^{-1}$ to $4{ }^{\circ} \mathrm{C}$ above ambient is not sufficient to induce a substantial oxidative challenge in S. pistillata. We provide some of the first evidence that regulation of coral enzymatic antioxidants can vary significantly depending on habitat, and, in terms of determining bleaching susceptibility, our results suggest a significant role for the host's differential regulation of cellular redox status.

Keywords Coral bleaching - Cnidarian-dinoflagellate symbiosis - Symbiodinium - Stylophora pistillata . Oxidative stress $\cdot$ Climate change

\section{Introduction}

The productivity of coral reefs depends on a symbiosis between reef corals and photosynthetic dinoflagellates (Symbiodinium) (Muscatine and Hand 1958; Davy et al. 2012). Despite their ecological success, reef corals are sensitive to high temperature and high light, which induce a pathology known as coral bleaching. Bleaching describes the whitening of coral tissues due to the loss of symbiont cells and pigments (Goreau 1990; Lesser 2011). The 
consequences of prolonged/intense bleaching include reduced host growth and immunity (Mydlarz et al. 2010; Grottoli et al. 2014), as well as partial- or whole-colony mortality (Jones 2008). Bleaching responses are taxonomically and spatially heterogeneous, depending on the genetic identity of host and symbiont (Berkelmans and van Oppen 2006; Baird et al. 2008; Kenkel et al. 2013; Silverstein et al. 2014), life-history aspects of the symbiosis (Putnam et al. 2012), previous exposure to stress (Bellantuono et al. 2012; Guest et al. 2012) and habitat characteristics such as water depth and shading (Lesser et al. 1990; Glynn et al. 2001; Lesser and Farrell 2004; Fabricius 2006). Despite much effort, our understanding of corals' differing bleaching susceptibilities remains superficial, since it is unclear how they emerge from the regulation of fundamental aspects of coral cell biology (see Traylor-Knowles and Palumbi 2014).

One mechanism that could influence the coral bleaching response is the regulation of redox homeostasis, particularly the prevention of a redox imbalance (in favour of pro-oxidants) that might result from temperature and light stress (Lesser 1997, 2011). The initial site of stress is thought to be Symbiodinium chloroplasts, where excess heat and light inhibit light-harvesting and carbon-fixation mechanisms (Jones et al. 1998; Warner et al. 1999) and promote the generation of reactive oxygen species (ROS) (Lesser 2006). Initially, the ROS include molecules such as the superoxide anion $\left(\mathrm{O}_{2}^{--}\right)$- produced via the Mehler reaction at photosystem I-and singlet oxygen $\left({ }^{1} \mathrm{O}_{2}\right)$, a product of interactions between oxygen and triplet chlorophyll (Asada and Takahashi 1987; Krieger-Liszkay 2005). The high reactivity of $\mathrm{O}_{2}^{--}$and ${ }^{1} \mathrm{O}_{2}$, and their limited capacity for diffusion (Winterbourn 2008) mean that their effects are probably localised to the Symbiodinium cell. However, the host almost certainly generates its own superoxide during coral bleaching, driven in part by the effects of temperature on mitochondrial integrity (Dunn et al. 2012).

Corals and Symbiodinium possess antioxidant mechanisms that ordinarily keep cellular ROS concentrations within a tolerable range and thus play an important role in redox homeostasis (Lesser and Shick 1989; Nii and Muscatine 1997; Richier et al. 2005). These include components of the glutathione cycle as well as superoxide dismutase (SOD) enzyme, which converts superoxide to hydrogen peroxide $\left(\mathrm{H}_{2} \mathrm{O}_{2}\right)$ (Bowler et al. 1994; Halliwell 2006). $\mathrm{H}_{2} \mathrm{O}_{2}$ is particularly interesting in the context of an endosymbiosis, as it has a greater ability to travel through cell membranes than do other ROS, which are often polar (e.g., superoxide) and/or extremely reactive (e.g., hydroxyl radicals) (Winterbourn 2008). $\mathrm{H}_{2} \mathrm{O}_{2}$ is detoxified by a range of mechanisms including ascorbate peroxidase (APX) enzyme in Symbiodinium chloroplasts and by catalase (CAT) enzymes in both partners (Lesser et al. 1990; Krueger et al. 2014). Indeed, while cells employ numerous antioxidant strategies at any one time, the SOD-APX and SOD-CAT mechanisms are the dominant enzymatic antioxidant pathways in eukaryotes (Asada 1999; Halliwell 2006).

Bleaching in heat-/light-stressed corals is thought to result from symbiont antioxidant mechanisms becoming overwhelmed by endogenous ROS (Downs et al. 2002; Lesser 2006), with the resultant excess $\mathrm{H}_{2} \mathrm{O}_{2}$ causing damage to host and symbiont cells and/or activating host signalling pathways that lead to the degradation or ejection of the symbiont (Weis 2008; Tchernov et al. 2011). Intracellular ROS and reactive nitrogen species (RNS) concentrations vary among different Symbiodinium species during stress and may correlate negatively with thermal tolerance (Suggett et al. 2008; Hawkins and Davy 2012). Different Symbiodinium species also have differing antioxidant capacities (McGinty et al. 2012; Krueger et al. 2014), but little is known about intraspecific variability in Symbiodinium antioxidant regulation (e.g., in different environments). Significant variability in antioxidant regulation has also been observed for host species and phenotypes (Shick et al. 1995; Yakovleva et al. 2004; Pontasch et al. 2014). Yet, beyond a large number of short-term laboratory studies applying often rapid heating rates or UV stresses (Lesser 1996; Nii and Muscatine 1997; Lesser and Farrell 2004; Suggett et al. 2008; Tchernov et al. 2011), few investigations have addressed the possibility that differing redox buffering capacities might influence corals' susceptibilities to bleaching. This is particularly true regarding intraspecific spatial variability in bleaching responses during a thermal/ photic stress event (Glynn et al. 2001; Fabricius 2006).

The aim of this study was to investigate the links between abiotic stress, enzymatic antioxidant activity and bleaching in a reef coral sampled across a defined environmental gradient and exposed to both heat and light stress. We used the stress-sensitive coral Stylophora pistillata as a study organism, since its susceptibility to bleaching may differ with depth, depending on the identity of the in hospite Symbiodinium community (Sampayo et al. 2008). We hypothesised that high temperature and/or light stimulates corals' protective enzymatic antioxidant responses. Assuming photooxidative stress in the symbiont to be the primary event in the bleaching cascade (Warner et al. 1999; Lesser 2006), we predicted that antioxidant up-regulation would be visible initially in Symbiodinium cells and then subsequently in the host, and that it would be most apparent in corals sampled from shallow areas (exposed to naturally higher irradiances and potentially better able to respond to transitory increases in ROS generation). We also predicted that the protective enzymatic antioxidant response would precede the onset of bleaching (defined as the loss of symbiont cells and/or their pigments) and that a negative correlation would be apparent between the magnitude and timing of antioxidant response and the intensity of bleaching. Specifically, we expected 
corals from the shallow reef zone acclimated to high incident light to display greater levels of antioxidant up-regulation and undergo less intense bleaching than deep corals acclimated to low irradiances (and, hypothetically, lower ROS fluxes). Here, we report data that have implications for our understanding of the roles of temperature and light in driving coral antioxidant physiology, and the importance of antioxidant regulation in structuring the bleaching susceptibility of corals in different environments.

\section{Materials and methods}

\section{Collection, acclimation and treatment of coral fragments}

Eight colonies of Stylophora pistillata (brown colour morph) were sampled using SCUBA from the reef slope at Harry's Bommie, Heron Island, Great Barrier Reef $\left(23^{\circ} 26^{\prime} 43^{\prime \prime} \mathrm{S}\right.$, $151^{\circ} 54^{\prime} 53^{\prime \prime} \mathrm{E}$ ) across two depths [5-8 $\mathrm{m}$ (henceforth referred to as shallow) and 15-18 $\mathrm{m}$ (deep), $n=4$ colonies per depth]. Colonies (designated S1-S4 and D1-D4 for shallow and deep, respectively) were separated by at least $10 \mathrm{~m}$ (to minimise the likelihood of sampling genetic clones) and were sampled from the substrate using wire cutters. Care was taken to ensure that colonies were from similar habitats within each depth range and, to minimise within-colony variability, fragments were removed only from the outside of colonies. Coral fragments were transported to Heron Island Research Station fully immersed in light-proof containers, placed in flow-through aquaria under shade cloth (flow rate $3 \mathrm{~L} \mathrm{~min}^{-1}$, irradiance $100 \mu \mathrm{mol}$ photons $\mathrm{m}^{-2} \mathrm{~s}^{-1}$ ) and left for $24 \mathrm{~h}$. Subsequent fragmentation resulted in a collection of sixteen $3-$ to $5-\mathrm{cm}$ fragments per colony, each mounted onto 1-cm-long sections of pipe using epoxy putty (Aqua Knead-It; Selleys, Padstow, Australia). Aerial exposure was minimised, and fragments were immediately transferred to flow-through seawater tanks after mounting (flow rate $1 \mathrm{~L} \mathrm{~min}^{-1}$ ). Fragments were subsequently allowed to recover for $8 \mathrm{~d}$ at $28^{\circ} \mathrm{C}$ (mean $27.92{ }^{\circ} \mathrm{C} \pm 0.78 \mathrm{SD}$ ). Shade cloth was used to deliver light intensities comparable to those at the sampling depths [colonies D1-D4: ca. $10 \%$ of incident photosynthetically active radiation $(\mathrm{PAR})=$ low light; $\mathrm{S} 1-\mathrm{S} 4$ : ca. $25 \%$ of incident $\mathrm{PAR}=$ high light]. Midday light intensities at the sampling sites were determined by holding a light-sensitive HOBO logger (Onset Computer Corporation, Bourne, MA, USA) with the light-meter facing vertically upwards for $10 \mathrm{~min}$ at a depth of either $6 \mathrm{~m}$ or $16 \mathrm{~m}$. Measured irradiances (100 and $500 \mu \mathrm{mol}$ photons $\mathrm{m}^{-2} \mathrm{~s}^{-1}$, respectively) were similar to those reported previously for this site (Sampayo et al. 2008).

The response of corals to elevated temperature is strongly influenced by irradiance (Lesser and Farrell 2004).
We therefore applied a reciprocal transplant experimental design, whereby fragments from each colony were haphazardly transferred to novel photic environments (i.e., deep fragments to high light and shallow fragments to low light). To control for effects of handling, control fragments were removed and replaced in their original positions, with aerial exposure minimised to no more than a few seconds. Half of the fragments were heated by $1{ }^{\circ} \mathrm{C} \mathrm{d}^{-1}$ to $32{ }^{\circ} \mathrm{C}$ (mean $31.7^{\circ} \mathrm{C} \pm 0.59 \mathrm{SD}$; Fig. 1a), and water temperatures were monitored using HOBO loggers (10 min sampling interval). Maximum temperature in the heated tank was maintained for $4 \mathrm{~d}$. Fragments were rotated and moved daily within each treatment, and the experiment was terminated after $7 \mathrm{~d}$. Incident PAR was recorded using a light metre (LI-COR Quantum LI-189 with cosine sensor; LICOR Inc., Lincoln, NE, USA).

\section{In hospite symbiont chlorophyll $a$ fluorescence}

Photosystem II (PSII) efficiency was measured daily using pulse amplitude modulation fluorometry (Diving-PAM, Walz, Effeltrich, Germany). Effective $\left(F_{q}{ }^{\prime} / F_{m}{ }^{\prime}\right)$ and maximum $\left(F_{v} / F_{m}\right)$ quantum yields were recorded at noon and $30 \mathrm{~min}$ after sunset, respectively. Nonphotochemical quenching was not calculated, as light- and dark-adapted measurements of identical locations on the same fragment could not be guaranteed.

\section{Fragment sampling and processing}

Coral fragments (one from each of four replicate colonies per treatment) were sampled shortly after midday at $t=0$, 3,5 and $7 \mathrm{~d}$ after temperature ramping. Fragments were snap-frozen in liquid $\mathrm{N}_{2}$ and stored at $-80{ }^{\circ} \mathrm{C}$. All subsequent steps were carried out at $4{ }^{\circ} \mathrm{C}$ or on ice, and reagents were obtained from Sigma-Aldrich (Auckland, New Zealand) unless otherwise indicated.

Coral tissue was removed by airbrushing into $5-10 \mathrm{~mL}$ of lysing buffer $(50 \mathrm{mM}$ potassium phosphate, $0.1 \mathrm{mM}$ EDTA, $10 \%$ [v/v] glycerol, $\mathrm{pH}$ 7.0). The tissue suspension was homogenised for $10 \mathrm{~s}$ with a rotor-stator homogeniser (Labserv D-130, Thermo Fisher Scientific, Albany, New Zealand), and duplicate aliquots were removed for Symbiodinium pigment and density analysis, respectively. An additional $100-\mu \mathrm{L}$ sample was removed and stored at $-80{ }^{\circ} \mathrm{C}$ for Symbiodinium genotyping. The aliquot for pigment analysis was centrifuged $(3000 \times g$, $5 \mathrm{~min})$, the supernatant removed and the algal pellet stored at $-20{ }^{\circ} \mathrm{C}$ in the dark. The symbiont density sample was fixed with $10 \mu \mathrm{L}$ Lugol's solution. The remaining coral homogenate was centrifuged $(1500 \times g, 5 \mathrm{~min})$, and the supernatant (host fraction) transferred to a clean $15-\mathrm{mL}$ tube. The algal pellet was snap-frozen in liquid $\mathrm{N}_{2}$ and stored at $-80{ }^{\circ} \mathrm{C}$. 




Fig. 1 Acclimation and treatment of Stylophora pistillata fragments sampled from deep (15-18 $\mathrm{m}$ ) and shallow (5-8 m) communities at Heron Island, Great Barrier Reef. a Temperature profiles of control and heating treatments during acclimation and experimental phases,

The host fraction was centrifuged at high speed in order to remove particulates $(16,000 \times g, 10 \mathrm{~min})$, snap-frozen in liquid $\mathrm{N}_{2}$ and stored at $-80{ }^{\circ} \mathrm{C}$.

Symbiodinium pellets were thawed on ice and washed four times with lysing buffer by repeated centrifugation $(1500 \times g, 5 \mathrm{~min})$. Cells were finally resuspended in $0.6 \mathrm{~mL}$ lysing buffer with $50 \mathrm{mg}$ glass beads $(710-1180 \mu \mathrm{m}$; Sigma-Aldrich, Auckland, New Zealand) and lysed in a bead mill (Tissuelyser LT, Qiagen Inc., Hilden, Germany) for $3 \mathrm{~min}$ at $50 \mathrm{~Hz}$. Lysate was visually inspected to confirm cellular disintegration and centrifuged $(16,000 \times g$, $10 \mathrm{~min}$ ) to remove particulates. The supernatant was removed, snap-frozen in liquid $\mathrm{N}_{2}$ and stored at $-80{ }^{\circ} \mathrm{C}$.

\section{Identification of Symbiodinium ITS2 types}

Frozen Symbiodinium cells (from $t=0$ fragments under $28{ }^{\circ} \mathrm{C} /$ low light [deep] or $28{ }^{\circ} \mathrm{C} /$ high light [shallow]) were lysed in a bead mill (see above). Genomic DNA was extracted following the methods of Stat et al. (2009), and the ITS2 region was amplified using the primers ITSintfor2 and ITS2revclamp (LaJeunesse 2002). PCR amplicons were initially analysed using agarose gel electrophoresis $(1.5 \%$ w/v) and then cloned using the TOPO TA Cloning Kit with One Shot Mach1 T1 E. coli (Life Technologies, Auckland, New Zealand) following the recommended procedures. Cells were grown overnight at $37{ }^{\circ} \mathrm{C}$ on Luria-Bertani (LB) agar plates $\left(50 \mu \mathrm{g} \mathrm{mL}^{-1}\right.$ ampicillin). Ten white colonies (indicating successful insertion of PCR amplicons) were selected and grown overnight in LB-ampicillin at $37^{\circ} \mathrm{C}$. Cells were collected by centrifugation $(4500 \times g, 10 \mathrm{~min})$, and the DNA was extracted using the PureLink Quick Plasmid MiniPrep Kit (Life Technologies, Auckland, New Zealand). Plasmid ITS2 inserts were then reamplified (forward primer as above, reverse primer ITSR: 5'-GGG ATC CAT ATG CTT AAG

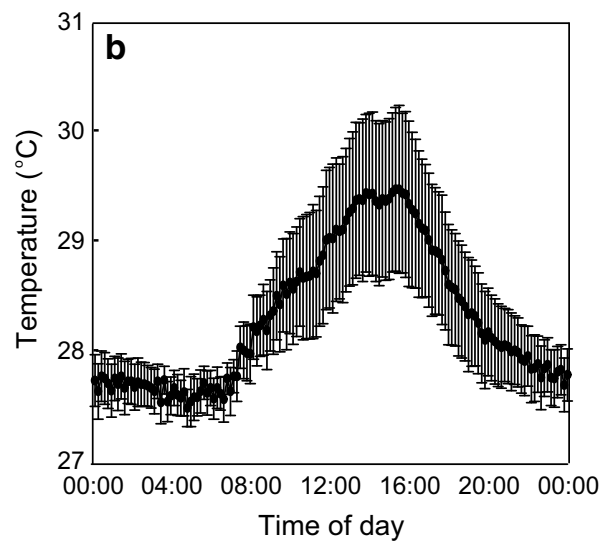

with grey bars indicating mean dawn-dusk incident photosynthetically active radiation (PAR). b Diurnal temperature variation experienced by fragments maintained in control conditions. Values are means $\pm 95 \%$ confidence intervals

TTC AGC GGG T-3'), purified (ExoSAP-IT; Affymetrix, Santa Clara, CA, USA) and sequenced in both directions by Macrogen Inc. (Seoul, South Korea). Sequences for each of five clones per colony were assigned to ITS2 types by comparison with the GeoSymbio database for clade C Symbiodinium (Franklin et al. 2012) using a BLASTn algorithm in the software package Geneious.

\section{Quantification of bleaching in coral fragments}

Symbiodinium densities were quantified using visual haemocytometer counts $(100 \times$ magnification, $n \geq 6$ per sample; Improved Neubauer, Boeco, Germany). Cell numbers were normalised to coral fragment surface area, measured using a single-dip method with paraffin wax (Veal et al. 2010). Symbiont chlorophyll (chl) $a$ content was quantified using a N,N-dimethylformamide extraction and the extinction coefficients of Porra et al. (1989).

\section{Assessments of antioxidant enzyme activities}

Host enzyme activities were normalised to soluble protein concentration, calculated using a modified Bradford assay following Ernst and Zor (2010). Symbiodinium enzyme activity was calculated per cell, by relating specific enzyme activity to mean protein content per cell. Unless otherwise stated, one unit of enzyme activity was defined as the consumption of $1 \mu \mathrm{mol}$ substrate $\min ^{-1}$ at $25^{\circ} \mathrm{C}$.

Total SOD activity of host and Symbiodinium fractions was quantified using a riboflavin/nitroblue tetrazolium assay in a microtiter plate format (Beauchamp and Fridovich 1971). Ascorbate peroxidase activity (APX) was quantified as the consumption of ascorbate $(0.3 \mathrm{mM})$ in a reaction buffer containing EDTA $(0.1 \mathrm{mM})$, potassium phosphate $(50 \mathrm{mM}, \mathrm{pH} 7.0)$ and $\mathrm{H}_{2} \mathrm{O}_{2}(0.1 \mathrm{mM})$ following 
the methods of Nakano and Asada (1981). SOD and APX assays are described in detail by Krueger et al. (2014).

CAT activity was quantified by incubating $100 \mu \mathrm{L}$ of homogenate/lysate in a final reaction volume of $700 \mu \mathrm{L}$ containing $14 \mathrm{mM} \mathrm{H} \mathrm{H}_{2} \mathrm{O}_{2}$ in buffer $(50 \mathrm{mM}$ potassium phosphate, $\mathrm{pH} 7.0,0.1 \mathrm{mM}$ EDTA). Host samples were diluted tenfold with lysing buffer prior to measurement. Absorbance at $240 \mathrm{~nm}$ was monitored in a quartz cuvette for $3 \mathrm{~min}$ at $25^{\circ} \mathrm{C}$ (UV-Vis spectrophotometer, Shimadzu Corp., Kyoto, Japan), and $\mathrm{H}_{2} \mathrm{O}_{2}$ removal rates were calculated using an extinction coefficient of $43.6 \mathrm{M}^{-1} \mathrm{~cm}^{-1}$ (Beers and Sizer 1952).

\section{Statistical analysis}

Responses to experimental heating and irradiance of Symbiodinium PSII efficiency, chlorophyll $a$ content, cell density, APX-, SOD- and CAT-like enzyme activities, and host SOD and CAT activities were investigated using a restricted-estimate maximum-likelihood (REML) linear mixed model (LMM; with day, temperature, light intensity and depth as fixed factors). Colony was included as a random factor to quantify genotypic effects, the magnitude of which are presented as $\mathrm{R}^{2}$ values (reflecting a percentage of explained variance). Covariance structures were determined for each variable by comparing Akaike Information Criterion (AIC) values across multiple iterations of the model. The model was then iterated further through the stepwise removal of nonsignificant interaction terms. All statistically significant effects are reported here $(\alpha \leq 0.05$; see Electronic Supplementary Materials, ESM, Tables S1 and S2 for full LMM outputs). Post hoc comparisons were conducted between temperature treatments (at each level of day, depth and/or light intensity) using a Bonferroni adjustment for multiple comparisons. Hypothesis testing was carried out using SPSS Statistics v.20 (IBM, Armonk, NY, USA), and data were transformed where necessary in order to fulfil the assumptions of parametric tests (see Tables 1 and 2).

\section{Results}

\section{In hospite Symbiodinium phylotypes}

Cloned sequences of Symbiodinium ITS2 fragments generally differed between the two depth groups (BLASTn, best-fit $E$ value $<1 \times 10^{-131}$ for all sequences). Shallow colonies contained either ITS2-type C35/a (three colonies), or types $\mathrm{C} 78$ and $\mathrm{C} 1$ (one colony). ITS2 sequences amplified from deep-sampled colonies matched C79 (two colonies), C8a and C1 (one colony) and C3, C79 and C35/a (one colony).

\section{Experimental conditions, photoinhibition and bleaching in $S$. pistillata}

Conditions varied over the experimental period, particularly with regard to incident PAR intensity, which increased over days 1-3 (Fig. 1a) and probably contributed to the high temperature variability in the control tank (Fig. 1a). However, the mean temperature in this tank-measured over the duration of the experiment-remained below $30{ }^{\circ} \mathrm{C}$ throughout the diurnal cycle and decreased to approximately $27.5^{\circ} \mathrm{C}$ overnight (Fig. 1b). These temperatures are characteristic of late-summer conditions at Heron Island (AIMS; http://data.aims.gov.au/aimsrtds/station.xhtml?station=130).

Exposure to elevated temperature and irradiance caused declines in Symbiodinium PSII efficiency in both depth groups (Fig. 2). In the case of $F_{v} / F_{m}$, responses to heating were influenced by irradiance (day $\times$ temperature $\times$ light interaction; Table 1) but not by depth. In contrast, temperature-induced declines in $F_{q}^{\prime} / F_{m}{ }^{\prime}$ were unaffected by irradiance but differed significantly between depth groups (day $\times$ temperature $\times$ depth interaction; Table 1). This was manifested as earlier and more pronounced decreases in $F_{q}{ }^{\prime} / F_{m}{ }^{\prime}$ of deep fragments relative to those in the shallow group (Fig. 2a-d).

Corals from both depths suffered bleaching due to high temperature and/or light. Symbiodinium chl $a$ content declined following heating (Fig. 3a, b; Table 1), but this response was independent of light or depth. However, chl $a$ content was generally lower under high irradiance (main effect of light; Table 1). Symbiodinium cell densities declined in both depth groups under elevated temperature and light (Fig. 3c, d), and these declines differed between deep and shallow colonies (Table 1). For example, after $7 \mathrm{~d}$ at high temperature/light, fragments from deep colonies had lost $85 \%$ of their initial Symbiodinium population versus only $50 \%$ in shallow fragments. These differences were less apparent following heating under low irradiance, where deep and shallow colonies lost similar proportions of symbionts (ca. $50 \%$ ).

\section{Enzymatic antioxidant activity in $S$. pistillata under heat and light stress}

Responses of antioxidant enzymes to treatment were highly variable, depending both on the specific treatment and the respective enzyme. Symbiodinium SOD activity responded to experimental heating and manipulated irradiance in a manner that differed significantly between depth groups (Fig. 4a, b; Table 2). While this is clear when the SOD activities of Symbiodinium in deep and shallow colonies are compared within the same treatment (e.g., heating under low light; Fig. 4a), the overall pattern of Symbiodinium SOD activity was similar across both groups. For 
Table 1 Statistical analysis of photosystem II (PSII) efficiency and bleaching of Stylophora pistillata colonies sampled from shallow and deep areas of reef slope ( $n=4$ colonies per depth) at Heron Island, Great Barrier Reef, Australia

\begin{tabular}{|c|c|c|c|c|}
\hline Parameter & $\begin{array}{l}\text { Colony effect } \\
\left(R^{2}\right)(\%)\end{array}$ & Test & $F$ statistic $_{(d f)}$ & $P$ \\
\hline \multirow[t]{8}{*}{ Effective quantum yield of PSII $-F_{\mathrm{q}}{ }^{\prime} / F_{\mathrm{m}}{ }^{\prime}$} & \multirow[t]{8}{*}{7.9} & Depth & $10.209_{(1,29.64)}$ & 0.003 \\
\hline & & Temperature & $70.574_{(1,29.64)}$ & $<0.001$ \\
\hline & & Light & $62.044_{(1,29.64)}$ & $<0.001$ \\
\hline & & Day & $29.721(8,69.39)$ & $<0.001$ \\
\hline & & Day $\times$ Depth & $2.831_{(8,69.39)}$ & 0.009 \\
\hline & & Day $\times$ Temperature & $14.027(8,69.38)$ & $<0.001$ \\
\hline & & Day $\times$ Light & $3.156_{(8,69.39)}$ & 0.004 \\
\hline & & Day $\times$ Temperature $\times$ Depth & $2.720_{(8,69.39)}$ & 0.011 \\
\hline \multirow[t]{8}{*}{ Maximum quantum yield of PSII $F_{v} / F_{m}$} & \multirow[t]{8}{*}{13} & Depth & $12.378_{(1,27.71)}$ & 0.002 \\
\hline & & Temperature & $38.863(1,27.71)$ & $<0.001$ \\
\hline & & Light & $33.846_{(1,27.71)}$ & $<0.001$ \\
\hline & & Day & $15.194(7,59.85)$ & $<0.001$ \\
\hline & & Day $\times$ Depth & $3.6044_{(7,59.85)}$ & 0.003 \\
\hline & & Day $\times$ Temperature & $9.232(7,59.85)$ & $<0.001$ \\
\hline & & Day $\times$ Light & $3.009(7,59.86)$ & 0.009 \\
\hline & & Day $\times$ Temperature $\times$ Light & $2.367(7,59.86)$ & 0.033 \\
\hline \multirow[t]{4}{*}{ Symbiont chlorophyll $a$ content (pg cell ${ }^{-1}$ ) } & \multirow[t]{4}{*}{10.5} & Temperature & $20.453(1,35.85)$ & $<0.001$ \\
\hline & & Light & $22.576_{(1,35.774)}$ & $<0.001$ \\
\hline & & Day & $17.358_{(3,78.52)}$ & $<0.001$ \\
\hline & & Day $\times$ Temperature & $9.548_{(3,78.52)}$ & $<0.001$ \\
\hline \multirow[t]{5}{*}{ Symbiont density (cells $\mathrm{cm}^{-2}$ ) } & \multirow[t]{5}{*}{27.1} & Temperature & $9.845(1,23.85)$ & 0.004 \\
\hline & & Light & $9.881(1,23.84)$ & 0.004 \\
\hline & & Day & $12.899(3,59.69)$ & $<0.001$ \\
\hline & & Day $\times$ Depth & $4.335(3,59.69)$ & 0.008 \\
\hline & & Day $\times$ Temperature $\times$ Depth & $3.344_{(3,59.69)}$ & 0.025 \\
\hline
\end{tabular}

A linear mixed model was used to compare effects of the fixed factors Temperature, Light intensity, Depth and sampling Day over the 7-d experimental period. A restricted maximum likelihood (REML) model was used to test for the effect of the random factor Colony; the percentage of total variance explained by this factor is reported as an $R^{2}$ value. Due to space considerations, only terms with significant probability values $(\alpha=0.05)$ are reported. For full LMM model outputs, see ESM Table S1

example, SOD activity increased in all fragments over the first $3 \mathrm{~d}$ of the experiment [day 3 vs. day 0 (Bonferroni correction), $\left.F_{(3,69.83)}=21.611, p<0.001\right]$, but subsequently plateaued, and-in the absence of altered irradiance (shallow fragments under high light or deep fragments under low light)_it eventually declined. Symbiodinium APX- and CAT-like activities responded similarly, in that significant changes in activity were only observed when fragments were heated in combination with manipulated irradiance (Fig. 4c-f). However, an interactive effect of depth was only observed for APX (Table 2), with treatment-induced responses most pronounced in the deep colonies.

Inclusion of colony as a random factor in the LMM analysis revealed that genotypic effects accounted for $<3 \%\left(R^{2}<0.03\right)$ of the observed variance in Symbiodinium SOD activity, and 17.4 and $20.7 \%$ for APX- and CAT-like activities, respectively. The high variability in APX activity was driven by differences between colonies 3 and 4 in both depth groups (lower APX activity in the former). In the case of CAT-like activity, substantial colony-level variability was only apparent in the shallow group. Here, under elevated temperature (regardless of irradiance), Symbiodinium cells in colony S4 maintained CAT-like activity at levels more than two times higher than those of any other colony.

Host SOD activity was insensitive to irradiance (Table 2), but was affected by heating (Fig. 5a, b; Table 2). However, this response was only apparent in fragments from deep colonies, where host SOD activity had decreased by day 7. Responses of host CAT activity to heating were also visible only in deep colonies, and here an interactive effect of light was observed (Fig. 5c, d; Table 2). For instance, host CAT activity was unaffected by high temperature alone (Fig. 5c), but increased significantly from day 5 when high temperatures were combined with elevated irradiance (Fig. 5d). Genotypic effects were also evident (Table 2), 
Table 2 Statistical analysis of host and symbiont antioxidant enzyme activity in Stylophora pistillata colonies sampled from shallow and deep areas of reef slope ( $n=4$ colonies per depth) at Heron Island, Great Barrier Reef, Australia

\begin{tabular}{|c|c|c|c|c|c|}
\hline Source & Parameter & $\begin{array}{l}\text { Colony effect } \\
\left(R^{2}\right)(\%)\end{array}$ & Test & $F$ statistic $_{(d f)}$ & $P$ \\
\hline \multirow{13}{*}{$\begin{array}{l}\vec{\Xi} \\
\text { है } \\
\text { है } \\
\text { है }\end{array}$} & \multirow{4}{*}{$\begin{array}{l}\text { Superoxide dismutase (SOD) } \\
\quad\left(\text { unit cell }{ }^{-1}\right)^{\mathrm{a}}\end{array}$} & \multirow[t]{5}{*}{2.5} & Light & $16.216_{(1,23.71)}$ & 0.001 \\
\hline & & & Day & $21.611(3,70.33)$ & $<0.001$ \\
\hline & & & Day $\times$ temperature & $2.977_{(3,70.33)}$ & 0.037 \\
\hline & & & Day $\times$ light $\times$ depth & $3.850_{(3,70.33)}$ & 0.013 \\
\hline & & & Day $\times$ temperature $\times$ light $\times$ depth & $3.463(3,70.33)$ & 0.021 \\
\hline & \multirow{5}{*}{$\begin{array}{l}\text { Ascorbate peroxidase } \\
(\mathrm{APX})\left(\text { unit cell }^{-1}\right)^{\mathrm{b}}\end{array}$} & \multirow[t]{5}{*}{16.9} & Temperature & $8.683_{(1,28.88)}$ & 0.006 \\
\hline & & & Light & $5.911_{(1,28.88)}$ & 0.021 \\
\hline & & & Day & $8.762(3,68.33)$ & $<0.001$ \\
\hline & & & Day $\times$ temperature & $5.099(3,68.33)$ & 0.003 \\
\hline & & & Day $\times$ temperature $\times$ light $\times$ depth & $3.273_{(3,68.33)}$ & 0.026 \\
\hline & \multirow[t]{3}{*}{ Catalase-like (CAT) $\left(\text { unit cell }^{-1}\right)^{\mathrm{b}}$} & \multirow[t]{3}{*}{24.5} & Day & $10.744_{(3,75.32)}$ & $<0.001$ \\
\hline & & & Day $\times$ temperature & $3.340_{(3,75.32)}$ & 0.024 \\
\hline & & & Day $\times$ depth & $3.808_{(3,75.32)}$ & 0.013 \\
\hline \multirow{9}{*}{$\begin{array}{l}\vec{w} \\
\text { 票 }\end{array}$} & \multirow{5}{*}{$\begin{array}{l}\text { Superoxide dismutase (SOD) } \\
\quad\left(\text { unit } \mathrm{mg}^{-1}\right)^{\mathrm{a}}\end{array}$} & \multirow[t]{5}{*}{29.4} & Depth & $6.864_{(1,24.20)}$ & 0.015 \\
\hline & & & Day & $6.926_{(3,73.49)}$ & $<0.001$ \\
\hline & & & Day $\times$ depth & $6.545_{(3,73.49)}$ & 0.001 \\
\hline & & & Day $\times$ temperature & $5.119(3,73.49)$ & 0.003 \\
\hline & & & Day $\times$ temperature $\times$ depth & $7.536_{(3,73.49)}$ & $<0.001$ \\
\hline & \multirow[t]{4}{*}{ Catalase (CAT) (unit $\left.\mathrm{mg}^{-1}\right)^{\mathrm{b}}$} & \multirow[t]{4}{*}{14.3} & Day & $7.121_{(3,70.80)}$ & $<0.001$ \\
\hline & & & Depth $\times$ temperature $\times$ light & $4.822_{(1,24.31)}$ & 0.038 \\
\hline & & & Day $\times$ temperature $\times$ light & $2.873(3,70.80)$ & 0.042 \\
\hline & & & Day $\times$ temperature $\times$ light $\times$ depth & $2.739_{(3,70.80)}$ & 0.049 \\
\hline
\end{tabular}

A linear mixed model was used to compare effects of the fixed factors Temperature, Light intensity, Depth and sampling Day over the 7-d experimental period. A restricted maximum likelihood (REML) model was used to test for the effect of the random factor Colony; the percentage of total variance explained by this factor is reported as an $R^{2}$ value. Due to space constraints, only significant terms $(\alpha=0.05)$ are reported. For full LMM model outputs, see ESM Table S2

a Square-root-transformed

b $\log _{10}$-transformed

accounting for 29 and $14.3 \%$ of observed variance in host SOD and CAT activities, respectively, across both depth groups.

\section{Discussion}

Coral bleaching susceptibility varies between and within coral species (Glynn et al. 2001; Berkelmans and van Oppen 2006; Fabricius 2006; Baird et al. 2008; Sampayo et al. 2008; Kenkel et al. 2013), and we lack a detailed understanding of the cellular mechanisms that contrive to determine a coral colony's stress tolerance. One mechanism that could affect bleaching susceptibility is the buffering of cellular redox status (Downs et al. 2002; Yakovleva et al. 2004; Lesser 2006). We examined this using the reef coral Stylophora pistillata, and our data suggest that the enzymatic regulation of cellular redox status is highly complex in this species. Here, we address firstly the timing and nature of observed antioxidant responses, and secondly the differential responses of $S$. pistillata colonies from different habitats.

\section{Changes in Symbiodinium SOD-, APX- and CAT- like activities are driven by light rather than temperature and occur after bleaching}

Significant treatment-induced changes in Symbiodinium SOD- or APX-/CAT-like activities were observed only on the final day of the experiment, $2 \mathrm{~d}$ after bleaching had occurred (declining Symbiodinium density and/or chl $a$ content) and $3 \mathrm{~d}$ after the onset of photoinhibition (declining PSII efficiency). Further, there was little evidence of an effect of temperature on the activity of any of the three enzymes quantified. Without the additional influence of light, heating resulted in lower SOD activity, while increases in APX- or CAT-like activity were only seen in fragments transplanted to a novel photic environment (i.e., shallow colonies exposed to low light and deep colonies to 

parameters $\left[F_{v} / F_{m}\right.$ : maximum quantum yield of PSII $(\mathbf{c}, \mathbf{d})$; $F_{q}{ }^{\prime} / F_{m}{ }^{\prime}$ : effective quantum yield of PSII $(\mathbf{a}, \mathbf{b})]$ of shallow- and deep-sampled Stylophora pistillata colonies exposed to experimental heating and/or elevated irradiance ( $H T$ high temperature, $C T$ control). Values are mean $\pm \mathrm{SE}$, and asterisks denote significance between temperatures (linear mixed model, $* p<0.05, n=4$ except for deep colonies at $t=6-7 \mathrm{~d}$ when $n=3$ )
Fig. 2 Photophysiological

\section{Low light}
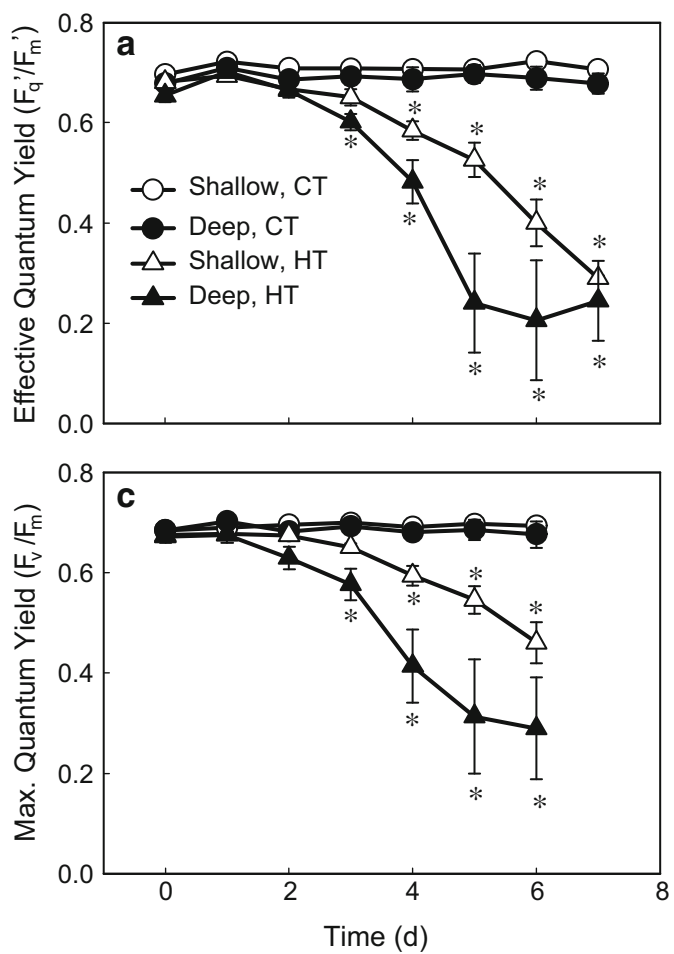

chlorophyll $a$ content per cell $(\mathbf{a}, \mathbf{b})$ and cell densities $(\mathbf{c}, \mathbf{d})]$ in colonies of Stylophora pistillata sampled from 5 to $8 \mathrm{~m}$ (shallow) and 15-18 m (deep), and exposed to elevated temperature and/or irradiance (HT high temperature, $C T$ control). Values are mean \pm SE. Panels a, b: shaded areas denote sampling days at which a significant difference between temperatures was observed within each depth group (linear mixed model, $p<0.05, n=4$ except for deep colonies at $32{ }^{\circ} \mathrm{C}$ on day 7 when $n=3$ ). Panels c, $\mathbf{d}$ : asterisks denote significance between temperatures (linear mixed model, $* p<0.05, * * p<0.01$, $* * * p<0.001, n=4$ except for deep colonies at on Day 7 when $n=3$ )
Low light



High light
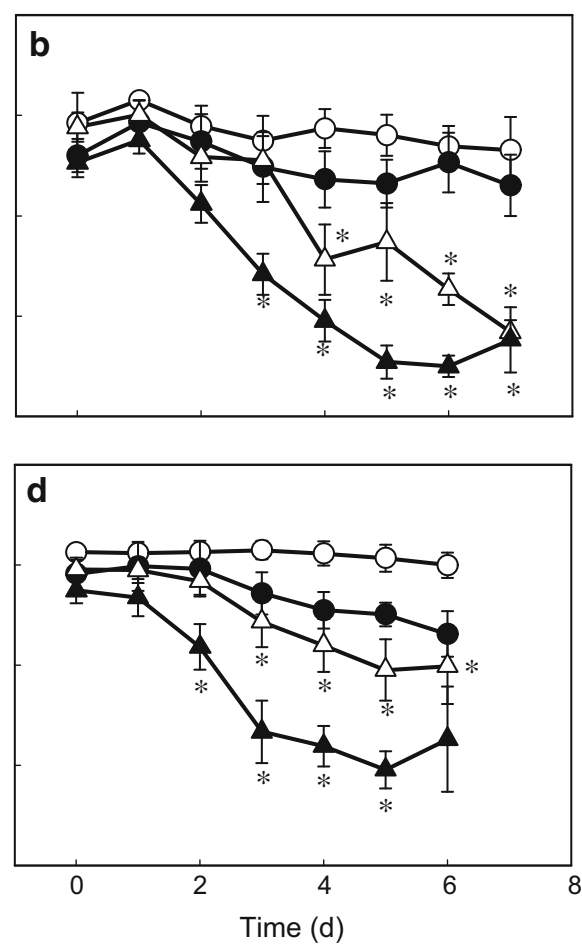

High light
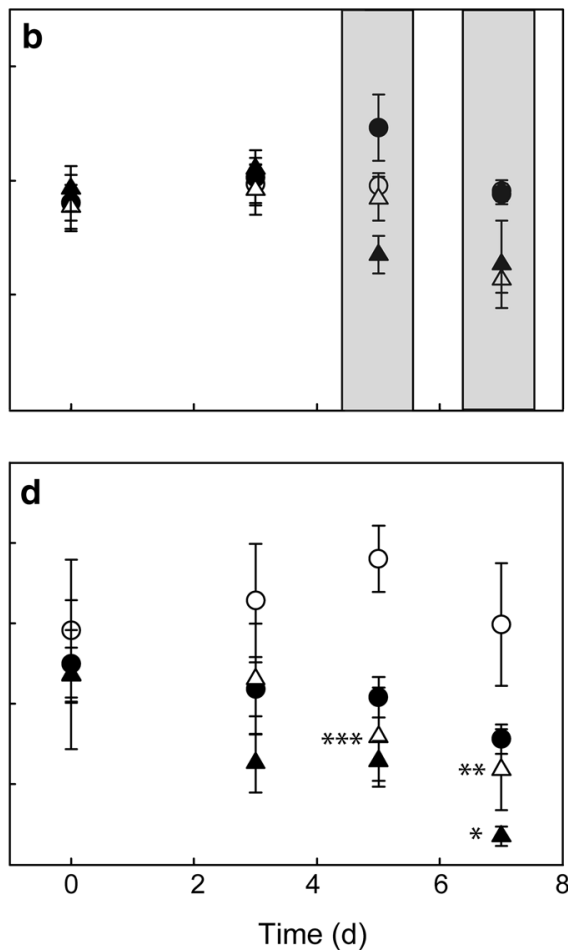

high light). Despite our efforts to acclimate the fragments before experimentation, this effect probably includes an influence of changing light spectrum as well as intensity.
One might expect these influences to more strongly affect fragments from deep colonies than those from the shallow group. However, the general similarity of light-driven 
Fig. 4 Antioxidant enzyme [SOD: superoxide dismutase (a, b); APX: ascorbate peroxidase (c, d); CAT: catalase-like (e, f)] activity per symbiont cell in Stylophora pistillata colonies sampled from 5-8 m (shallow) and 15-18 $\mathrm{m}$ (deep), and exposed to elevated temperature and/or irradiance (HT: high temperature, CT: control).

Values are mean $\pm \mathrm{SE}$. Asterisks in panels a-d denote significance between temperatures within each depth group and light level (linear mixed model, $* p<0.05$, ** $p<0.01, n=4$ except for deep colonies at $32{ }^{\circ} \mathrm{C}$ on day 7 when $n=3$ )
Low light
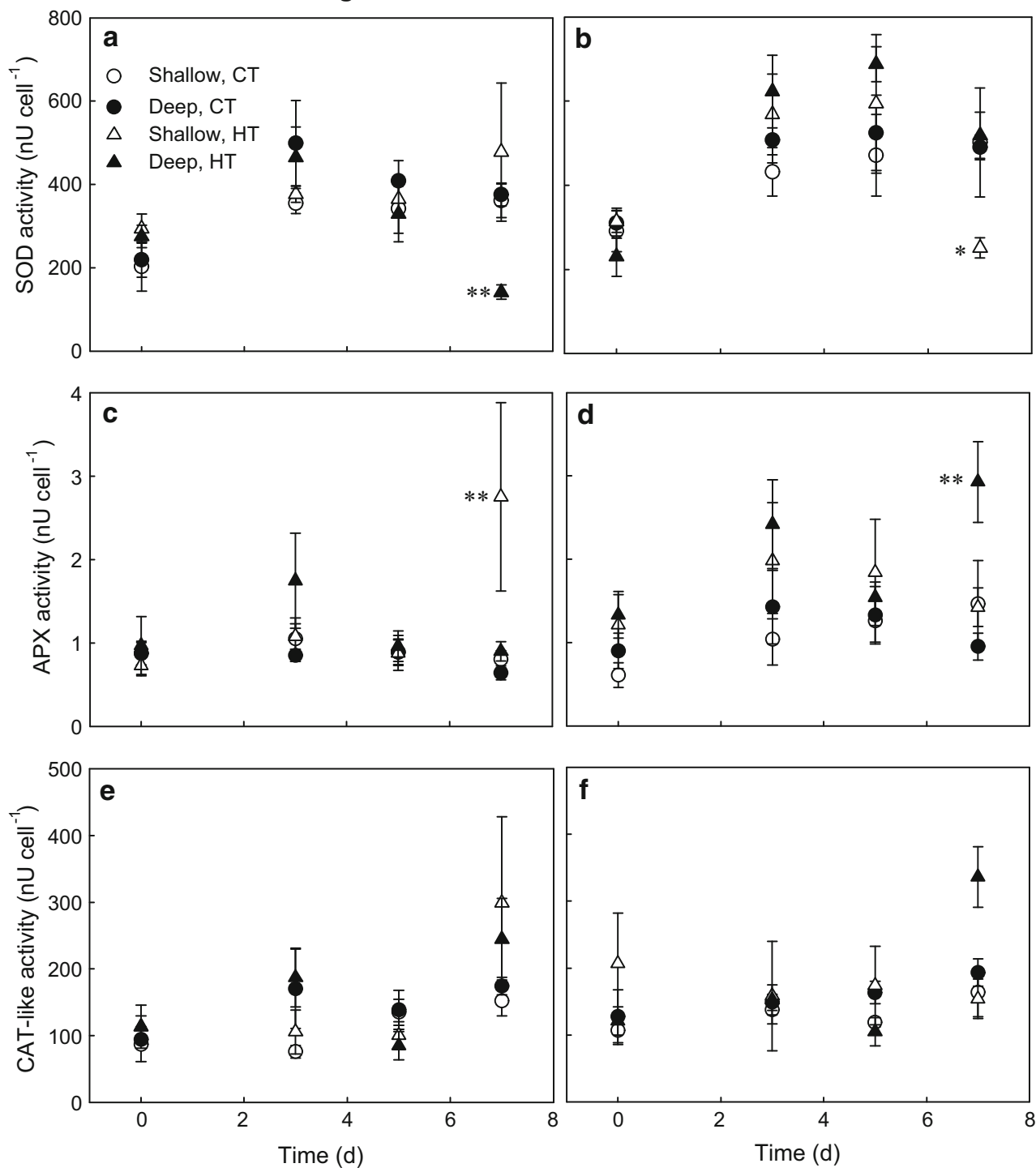

responses across depth groups (few significant light $\times$ depth effects; Table 2) suggests that this might not have been the case, and this lessens the likelihood of our conclusions being confounded by this uncontrolled factor. Overall, our findings are in agreement with those of previous studies that found irradiance to be a critical factor in structuring the Symbiodinium antioxidant network (e.g., Dykens and Shick 1982; Lesser and Shick 1989; Shick et al. 1995; Lesser 1996; Lesser and Farrell 2004; Richier et al. 2008). Indeed, it is possible that this high sensitivity to light could have masked any responses of SOD to temperature between days 0 and 3 of our experiment, when natural PAR intensity increased substantially.

We acknowledge that without measuring all components of the Symbiodinium redox regulatory network alongside upstream photoprotective mechanisms (Reynolds et al. 2008), we are unable to draw firm conclusions regarding the precise sequence of events occurring within the cells during stress. Certainly, an involvement of singlet oxygen and RNS in the photoinactivation of PSII (Krieger-Liszkay 2005; Hawkins and Davy 2012) would account for the anomaly of declining PSII yields in the absence of any apparent increases in SOD-, APX- or CAT-like activity. However, given that the activities of these enzymes are considered reliable indicators of the oxidative challenge facing a cell (Lesser et al. 1990; Asada 1999) and did respond to treatment in the latter stages of the experiment, we are confident in asserting at least that intracellular levels of $\mathrm{O}_{2}^{--}$and $\mathrm{H}_{2} \mathrm{O}_{2}$ in Symbiodinium were not substantially affected by high temperature until coral fragments had already bleached. The fact that this bleaching was itself driven by temperature rather than light (Table 1) suggests that symbiont antioxidant capacity might play only a minor role in influencing bleaching outcomes in $S$. 
Fig. 5 Specific activity of host antioxidant enzymes [SOD: superoxide dismutase $(\mathbf{a}, \mathbf{b})$; CAT: catalase $(\mathbf{c}, \mathbf{d})]$ in Stylophora pistillata colonies sampled from 5 to $8 \mathrm{~m}$ (shallow) and 15-18 m (deep), and exposed to elevated temperature and/or irradiance ( $H T$ high temperature, $C T$ control). Values are mean \pm SE. Asterisks in panel d denote significant differences between temperatures within each depth group and light level $(* * p<0.01)$, while shaded areas in panels $\mathbf{a}-\mathbf{b}$ denote the sampling days at which a significant difference between temperatures was observed within each depth group, regardless of light intensity (linear mixed model, $p<0.05$, $n=4$ except for deep colonies at $32{ }^{\circ} \mathrm{C}$ on day 7 when $n=3$ )

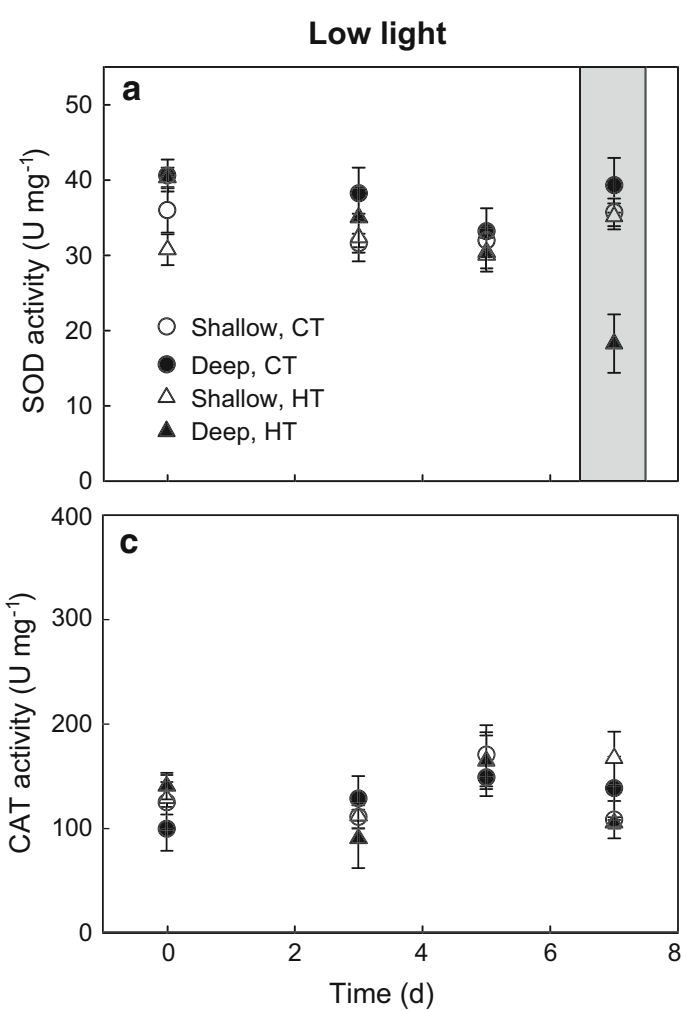

High light
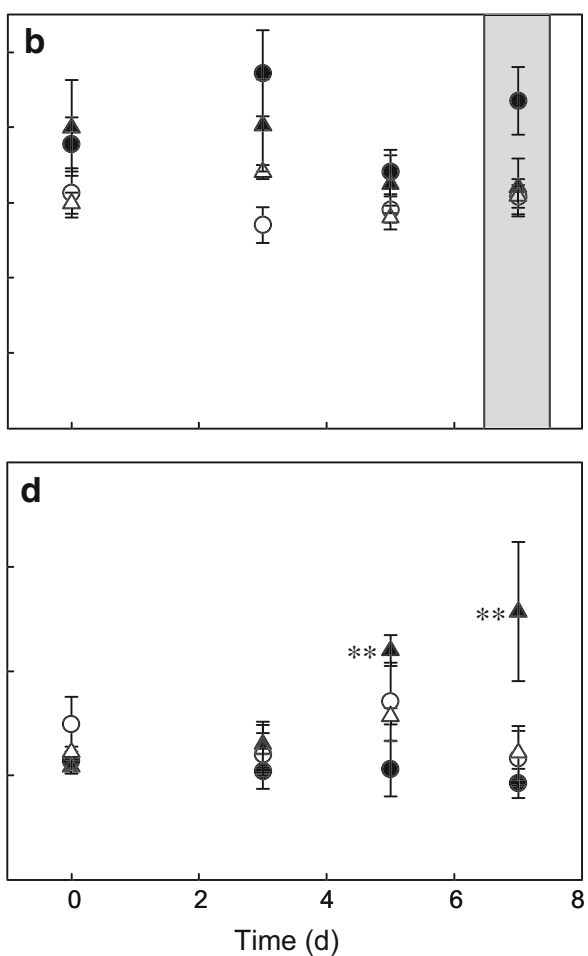

pistillata. Overall, our data support the hypothesis that prolonged and combined heat and light stresses induce ROS overproduction in the dinoflagellate symbionts of reef corals (Downs et al. 2002; Lesser 2006; Suggett et al. 2008), but they are also consistent with recent suggestions that photooxidative stress in these algae may not be a prerequisite for coral bleaching (Paxton et al. 2013; Tolleter et al. 2013; Hawkins et al. 2014).

\section{Regulating the oxidative challenge during bleaching: a greater role for the host?}

As discussed above, significant responses of Symbiodinium SOD-, APX- and CAT-like activities in Stylophora pistillata appeared to be driven largely by changes in irradiance and occurred only when corals were already bleached. Surprisingly, most fragments that bleached did so without an increase in host SOD (all fragments) or CAT activity (all shallow fragments and $50 \%$ of deep fragments). Taking into account the well-documented sensitivities of these enzymes to exogenous ROS and abiotic stress (Lesser and Shick 1989; Halliwell 2006), this finding suggests that bleaching in the majority of our fragments probably occurred in the absence of an $\mathrm{O}_{2}^{--}$- or $\mathrm{H}_{2} \mathrm{O}_{2}$-driven challenge to the host. We stress that this does not preclude these ROS from involvement in the bleaching cascade, but it does suggest that their concentrations were likely not sufficient to present a direct challenge to cellular integrity. One alternative pathway involves interactions of ROS with RNS such as nitric oxide (NO). These interactions are known to occur in symbiotic sea anemones under thermal stress (Hawkins and Davy 2013) and are thermodynamically favoured (Radi et al. 2001). Thus, under certain circumstances (e.g., the simultaneous production of $\mathrm{NO}$ and $\mathrm{O}_{2}^{-}$), the ROS in question could have physiologically relevant actions without accumulating to levels high enough to require enzymatic detoxification. As noted above, it is difficult to fully determine the role of ROS in the collapse of the coral-Symbiodinium association without measuring all components of the reef coral antioxidant network simultaneously (a significant task). Notwithstanding this limitation, the fact that observed increases in host CAT activity (in deep colonies on day 5 under high temperature/light) preceded the equivalent response of the Symbiodinium cells suggests that the symbionts in this case either lacked the ability to respond to endogenous $\mathrm{H}_{2} \mathrm{O}_{2}$ in the classical manner, or that host $\mathrm{H}_{2} \mathrm{O}_{2}$ generation preceded that of the symbiont. The former seems unlikely, as symbiont APX- and CAT-like activities did subsequently increase. Therefore, these findings lead us to propose that current models of oxidative stress in bleaching corals may require modification.

One such modification concerns the primacy of the symbiont in structuring corals' cellular redox status, much of the evidence for which has come from comparisons of symbiotic and aposymbiotic hosts (e.g., Yakovleva et al. 2009; Saragosti et al. 2010; Armoza-Zvuloni and Shaked 
2014), and symbiotic and aposymbiotic cells within the same host (e.g., Richier et al. 2006). Elevated ROS production, antioxidant activity and oxidative damage in symbiotic tissues are often taken as evidence that the ROS are symbiont-derived (e.g., Armoza-Zvuloni and Shaked 2014). However, they could equally reflect heightened ROS generation by the host in response to the presence of symbionts (perhaps as a result of higher oxygen tension in the light). Our quantification of antioxidant mechanisms was by no means exhaustive, but the significant disparity in enzymatic $\mathrm{H}_{2} \mathrm{O}_{2}$-detoxification capacities between host and symbiont (ESM Fig. S1; and see Nii and Muscatine 1997; Levy et al. 2006) suggests that (a) leakage of symbiont-derived $\mathrm{H}_{2} \mathrm{O}_{2}$ would represent a comparatively minor challenge to the host; and (b) $\mathrm{H}_{2} \mathrm{O}_{2}$ production by the host could damage the symbiont without causing excessive self-harm. Either way, it is clear that the host has an important role to play in determining the cellular redox environment in corals, and we therefore suggest that further efforts should be made to characterise host ROS production and detoxification during the early stages of a coral bleaching event.

\section{Differential regulation of Stylophora pistillata antioxidant activity occurs in the host and has little impact on thermal bleaching susceptibility}

The effect of depth on overall responses of the antioxidant network to heat and light stresses was stronger for host-level variables (CAT and SOD activities) than for symbiont-level parameters. We acknowledge that by pooling cells of multiple symbiont phylotypes from the same coral fragmentunavoidable with current methodologies-we may have underestimated the diversity of symbiont antioxidant responses. Conversely, in hospite shuffling of ITS2 types (Buddemeier and Fautin (1993)) might have exaggerated changes in Symbiodinium antioxidant activity, for example, if cells with a limited ability to up-regulate APX- or CATlike enzyme activity were preferentially expelled during bleaching. Additional work is needed to confirm whether this phenomenon occurs in bleaching corals (but see Pontasch et al. 2014). The high host-level variability seen here between depth groups can be explained in at least two ways: (a) our colonies represent two distinct species; (b) regulation of antioxidant enzymes is highly plastic in $S$. pistillata across its depth distribution; (c) S. pistillata antioxidant activity is determined by the identity of the in hospite symbiont.

Firstly, while pocilloporid corals harbour significant cryptic diversity across broad spatial scales (Bongaerts et al. 2010), it is unlikely that we sampled different species, since $S$. pistillata morphology is distinctive at this location (Sampayo et al. 2008). Whether the depth-dependent variability observed here reflects genetic divergence (Bongaerts et al. 2010), phenotypic plasticity in the classic sense (Dykens and Shick 1984; Shick et al. 1995; Pontasch et al. 2014), or an as-yet-unknown influence of symbiont identity on host antioxidant physiology, is a question that our experimental design does not directly address. It was certainly the case that colony-level physiological variability was comparatively higher among shallow colonies, despite Symbiodinium genotypic diversity being lower in this group. This suggests that - at least in the context of host enzymatic antioxidant activity-host plasticity might be more important than physiological divergence among closely related symbiont types in determining responses to stress.

The co-varying nature of the abiotic environment, Symbiodinium species distribution and host physiology makes robust investigations into corals' differing stress responses challenging. An optimal strategy is an experiment in which a dominant co-factor such as irradiance can be controlled. This investigation therefore provides important ecological context to the study of coral redox biology. Inconsistencies between our results and those of other investigations (e.g., the absence of temperature-induced up-regulation of symbiont antioxidant enzymes until late in the experiment [Lesser, 1996]) probably stem from the fact that corals' responses to stress depend on both the nature of the stressor (heating rate, for example) and the identities of the organisms involved (Downs et al. 2013). Certainly, the data presented here confirm that corals' cellular responses to stress can differ significantly depending on their habitats, and this has implications for population-level responses to thermal stress events. Further experimentation applying a range of ecologically relevant treatments is undoubtedly needed. Focusing on pre-bleaching cellular events in the host might more rapidly improve our understanding of reef corals' responses to stressful environments.

Acknowledgments We wish to thank the staff at Heron Island Research Station, University of Queensland, for their assistance with sampling and equipment maintenance, and Dr Olga Pantos for providing storage space for samples during transit. This work was carried out as part of a $\mathrm{PhD}$ project supported by a Commonwealth Scholarship awarded to TH, a Marsden Fund award (\#VUW0902) to SKD and PF, a Marsden-funded PhD scholarship to TK, and a Victoria University of Wellington Vice Chancellor's Strategic Research PhD Scholarship to SPW. Finally, we thank Dr Mark Warner, members of the Davy Lab and four anonymous reviewers for their constructive feedback.

\section{References}

Armoza-Zvuloni R, Shaked Y (2014) Release of hydrogen peroxide and antioxidants by the coral Stylophora pistillata to its external milieu. Biogeosci Discuss 11:33-59

Asada K (1999) The water-water cycle in chloroplasts: scavenging of active oxygen and dissipation of excess photons. Annu Rev Plant Physiol Plant Mol Biol 50:601-639 
Asada K, Takahashi M (1987) Production and scavenging of active oxygen in photosynthesis. In: Kyle DJ, Osmond CB, Arntzen CJ (eds) Photoinhibition. Elsevier, Amsterdam, pp 228-287

Baird AH, Bhagooli R, Ralph PJ, Takahashi S (2008) Coral bleaching: the role of the host. Trends Ecol Evol 24:16-20

Beauchamp C, Fridovich I (1971) Superoxide dismutase: improved assays and an assay applicable to acrylamide gels. Anal Biochem 44:276-287

Beers R, Sizer IW (1952) A spectrophotometric method for measuring the breakdown of hydrogen peroxide by catalase. J Biol Chem 195:133-140

Bellantuono AJ, Hoegh-Guldberg O, Rodriguez-Lanetty M (2012) Resistance to thermal stress in corals without changes in symbiont composition. Proc R Soc Lond B Biol Sci 279:1100-1107

Berkelmans R, van Oppen MJH (2006) The role of zooxanthellae in the thermal tolerance of corals: a 'nugget of hope' for coral reefs in an era of climate change. Proc R Soc Lond B Biol Sci 273:2305-2312

Bongaerts P, Riginos C, Ridgway T, Sampayo EM, van Oppen MJH, Englebert N, Vermeulen F, Hoegh-Guldberg O (2010) Genetic divergence across habitats in the widespread coral Seriatopora hystrix and its associated Symbiodinium. PLoS One 5:e10871

Bowler C, Van Camp W, Van Montagu M, Inze D (1994) Superoxide dismutase in plants. CRC Crit Rev Plant Sci 13:199-218

Buddemeier RW, Fautin DG (1993) Coral bleaching as an adaptive mechanism. Bioscience 43:320-326

Davy SK, Allemand D, Weis VM (2012) The cell biology of cnidarian-dinoflagellate symbiosis. Microbiol Mol Biol Rev 76:229-261

Downs CA, Fauth JE, Halas JC, Dustan P, Bemiss J, Woodley CM (2002) Oxidative stress and seasonal coral bleaching. Free Radic Biol Med 33:533-543

Downs CA, McDougall KE, Woodley CM, Fauth JE, Richmond RH, Kushmaro A, Gibb SW, Loya Y, Ostrander GK, KramarskyWinter E (2013) Heat-stress and light-stress induce different cellular pathologies in the symbiotic dinoflagellate during coral bleaching. PLoS One 8:e77173

Dunn SR, Pernice M, Green K, Hoegh-Guldberg O, Dove SG (2012) Thermal stress promotes host mitochondrial degradation in symbiotic cnidarians: are the batteries of the reef going to run out? PLoS One 7:e39024

Dykens JA, Shick JM (1982) Oxygen production by endosymbiotic algae controls superoxide dismutase activity in their animal host. Nature 297:579-580

Dykens JA, Shick JM (1984) Photobiology of the symbiotic sea anemone, Anthopleura elegantissima: defenses against photodynamic effects, and seasonal photoacclimatization. Biol Bull 167:683-697

Ernst O, Zor T (2010) Linearization of the Bradford protein assay. J Vis Exp 38:e1918

Fabricius KE (2006) Effects of irradiance, flow, and colony pigmentation on the temperature microenvironment around corals: implications for coral bleaching? Limnol Oceanogr 51:30-37

Franklin EC, Stat M, Pochon X, Putnam HM, Gates RD (2012) GeoSymbio: a hybrid, cloud-based web application of global geospatial bioinformatics and ecoinformatics for Symbiodiniumhost symbioses. Mol Ecol Res 12:369-373

Glynn PW, Mate JL, Baker AC, Calderon MO (2001) Coral bleaching and mortality in Panama and Ecuador during the 1997-1998 El Nino-Southern oscillation event: spatial/temporal patterns and comparisons with the 1982-1983 event. Bull Mar Sci 69:79-109

Goreau TF (1990) Coral bleaching in Jamaica. Nature 343:417

Grottoli AG, Warner ME, Levas SJ, Aschaffenburg MD, Schoepf V, McGinley M, Baumann J, Matsui Y (2014) The cumulative impact of annual coral bleaching can turn some coral species winners into losers. Glob Chang Biol 20:3823-3833
Guest JR, Baird AH, Maynard JA, Muttaqin E, Edwards AJ, Campbell SJ, Yewdall K, Affendi YA, Chou LM (2012) Contrasting patterns of coral bleaching susceptibility in 2010 suggest an adaptive response to thermal stress. PLoS One 7:e33353

Halliwell B (2006) Reactive species and antioxidants. Redox biology is a fundamental theme of aerobic life. Plant Physiol 141:312-322

Hawkins TD, Davy SK (2012) Nitric oxide production and tolerance differ among Symbiodinium types exposed to heat stress. Plant Cell Physiol 53:1889-1898

Hawkins TD, Davy SK (2013) Nitric oxide and coral bleaching: is peroxynitrite generation required for symbiosis collapse? J Exp Biol 216:3185-3188

Hawkins TD, Krueger TK, Becker S, Fisher PL, Davy SK (2014) Differential nitric oxide synthesis and host apoptotic events correlate with bleaching susceptibility in reef corals. Coral Reefs $33: 141-153$

Jones RJ (2008) Coral bleaching, bleaching-induced mortality, and the adaptive significance of the bleaching response. Mar Biol 154:65-80

Jones RJ, Hoegh-Guldberg O, Larkum AWD, Schreiber U (1998) Temperature-induced bleaching of corals begins with impairment of the $\mathrm{CO}_{2}$ fixation mechanism in zooxanthellae. Plant Cell Environ 21:1219-1230

Kenkel CD, Goodbody-Gringley G, Caillaud D, Davies SW, Bartels E, Matz MV (2013) Evidence for a host role in thermotolerance divergence between populations of the mustard hill coral (Porites astreoides) from different reef environments. Mol Ecol 22:4335-4348

Krieger-Liszkay A (2005) Singlet oxygen production in photosynthesis. J Exp Bot 56:337-346

Krueger T, Becker S, Pontasch S, Dove S, Hoegh-Guldberg O, Leggat W, Fisher PL, Davy SK (2014) Antioxidant plasticity and thermal sensitivity in four types of Symbiodinium sp. J Phycol 50:1035-1047

LaJeunesse TC (2002) Diversity and community structure of symbiotic dinoflagellates from Caribbean coral reefs. Mar Biol 141:387-400

Lesser MP (1996) Elevated temperatures and ultraviolet radiation cause oxidative stress and inhibit photosynthesis in symbiotic dinoflagellates. Limnol Oceanogr 41:271-283

Lesser MP (1997) Oxidative stress causes coral bleaching during exposure to elevated temperatures. Coral Reefs 16:187-192

Lesser MP (2006) Oxidative stress in marine environments. Annu Rev Physiol 68:253-278

Lesser MP (2011) Coral bleaching: causes and mechanisms. In: Dubinsky TJ, Stamler JS (eds) Coral reefs: an ecosystem in transition. Springer, Berlin, pp 405-419

Lesser MP, Shick JM (1989) Photoadaption and defenses against oxygen-toxicity in zooxanthellae from natural-populations of symbiotic cnidarians. J Exp Mar Biol Ecol 134:129-141

Lesser MP, Farrell JH (2004) Exposure to solar radiation increases damage to both host tissues and algal symbionts of corals during thermal stress. Coral Reefs 23:367-377

Lesser MP, Stochaj WR, Tapley DW, Shick JM (1990) Bleaching in coral reef anthozoans: effects of irradiance, ultraviolet radiation, and temperature on the activities of protective enzymes against active oxygen. Coral Reefs 8:225-232

Levy O, Achituv Y, Yacobi YZ, Stambler N, Dubinsky Z (2006) The impact of spectral composition and light periodicity on the activity of two antioxidant enzymes (SOD and CAT) in the coral Favia favus. J Exp Mar Biol Ecol 328:35-46

McGinty ES, Pieczonka J, Mydlarz LD (2012) Variations in reactive oxygen release and antioxidant activity in multiple Symbiodinium types in response to elevated temperature. Microb Ecol 64:1000-1007 
Muscatine L, Hand C (1958) Direct evidence for the transfer of materials from symbiotic algae to the tissues of a coelenterate. Proc Natl Acad Sci U S A 44:1259-1263

Mydlarz LD, McGinty ES, Harvell CD (2010) What are the physiological and immunological responses of coral to climate warming and disease? J Exp Biol 213:934-945

Nakano Y, Asada K (1981) Hydrogen peroxide is scavenged by ascorbate-specific peroxidase in spinach chloroplasts. Plant Cell Physiol 22:867-880

Nii CM, Muscatine L (1997) Oxidative stress in the symbiotic sea anemone Aiptasia pulchella (Carlgren, 1943): contribution of the animal to superoxide ion production at elevated temperature. Biol Bull 192:444-456

Paxton CW, Davy SK, Weis VM (2013) Stress and death of host cells play a role in cnidarian bleaching. J Exp Biol 216:2813-2820

Pontasch S, Hill R, Deschaseaux E, Fisher P, Davy S, Scott A (2014) Photochemical efficiency and antioxidant capacity in relation to Symbiodinium genotype and host phenotype in a symbiotic cnidarian. Mar Ecol Prog Ser 516:195-208

Porra R, Thompson W, Kriedemann P (1989) Determination of accurate extinction coefficients and simultaneous equations for assaying chlorophylls $a$ and $b$ extracted with four different solvents: verification of the concentration of chlorophyll standards by atomic absorption spectroscopy. Biochim Biophys Acta 975:384-394

Putnam HM, Stat M, Pochon X, Gates RD (2012) Endosymbiotic flexibility associates with environmental sensitivity in scleractinian corals. Proc R Soc Lond B Biol Sci 279:4352-4361

Radi R, Peluffo G, Alvarez MN, Naviliat M, Cayota A (2001) Unraveling peroxynitrite formation in biological systems. Free Radic Biol Med 30:463-488

Reynolds JM, Bruns BU, Fitt WK, Schmidt GW (2008) Enhanced photoprotection pathways in symbiotic dinoflagellates of shallow-water corals and other cnidarians. Proc Natl Acad Sci U S A 105:13674-13678

Richier S, Furla P, Plantivaux A, Merle PL, Allemand D (2005) Symbiosis-induced adaptation to oxidative stress. J Exp Biol 208:277-285

Richier S, Sabourault C, Courtiade J, Zucchini N, Allemand D, Furla $\mathrm{P}$ (2006) Oxidative stress and apoptotic events during thermal stress in the symbiotic sea anemone, Anemonia viridis. FEBS J 273:4186-4198

Richier S, Cottalorda J-M, Guillarme MMM, Fernandez C, Allemand D, Furla P (2008) Depth-dependent response to light of the reef building coral, Pocillopora verrucosa: implication of oxidative stress. J Exp Mar Biol Ecol 357:48-56

Sampayo EM, Ridgway T, Bongaerts P, Hoegh-Guldberg O (2008) Bleaching susceptibility and mortality of corals are determined by fine-scale differences in symbiont type. Proc Natl Acad Sci U S A 105:10444-10449

Saragosti E, Tchernov D, Katsir A, Shaked Y (2010) Extracellular production and degradation of superoxide in the coral Stylophora pistillata and cultured Symbiodinium. PLoS One 5:e12508

Shick JM, Lesser MP, Dunlap WC, Stochaj WR, Chalker BE, Won JW (1995) Depth-dependent responses to solar ultraviolet radiation and oxidative stress in the zooxanthellate coral Acropora microphthalma. Mar Biol 122:41-51

Silverstein RN, Cunning R, Baker AC (2014) Change in algal symbiont communities after bleaching, not prior heat exposure, increases heat tolerance of reef corals. Glob Chang Bio. 21:236-249

Stat M, Pochon X, Cowie ROM, Gates RD (2009) Specificity in communities of Symbiodinium in corals from Johnston Atoll. Mar Ecol Prog Ser 386:83-96

Suggett DJ, Warner ME, Smith DJ, Davey P, Hennige S, Baker NR (2008) Photosynthesis and production of hydrogen peroxide by Symbiodinium (Pyrrhophyta) phylotypes with different thermal tolerances. J Phycol 44:948-956

Tchernov D, Kvitt H, Haramaty L, Bibby TS, Gorbunov MY, Rosenfeld H, Falkowski PG (2011) Apoptosis and the selective survival of host animals following thermal bleaching in zooxanthellate corals. Proc Natl Acad Sci U S A 108:9905-9909

Tolleter D, Seneca F, DeNofrio J, Krediet C, Palumbi S, Pringle J, Grossman A (2013) Coral bleaching independent of photosynthetic activity. Curr Biol 23:1782-1786

Traylor-Knowles N, Palumbi SR (2014) Translational environmental biology: cell biology informing conservation. Trends Cell Biol 24:265-267

Veal CJ, Holmes G, Nunes M, Hoegh-Guldberg O, Osborne J (2010) A comparative study of methods for surface area and three dimensional shape measurement of coral skeletons. Limnol Oceanogr Methods 8:241-253

Warner ME, Fitt WK, Schmidt GW (1999) Damage to photosystem II in symbiotic dinoflagellates: a determinant of coral bleaching. Proc Natl Acad Sci U S A 96:8007-8012

Weis VM (2008) Cellular mechanisms of cnidarian bleaching: stress causes the collapse of symbiosis. J Exp Biol 211:3059-3066

Winterbourn CC (2008) Reconciling the chemistry and biology of reactive oxygen species. Nat Chem Biol 4:278-286

Yakovleva I, Bhagooli R, Takemura A, Hidaka M (2004) Differential susceptibility to oxidative stress of two scleractinian corals: antioxidant functioning of mycosporine-glycine. Comp Biochem Physiol B Biochem Mol Biol 139:721-730

Yakovleva IM, Baird AH, Yamamoto HH, Bhagooli R, Nonaka M, Hidaka M (2009) Algal symbionts increase oxidative damage and death in coral larvae at high temperatures. Mar Ecol Prog Ser 378:105-112 